\title{
Clinical Characterization of Traumatic Acute Interhemispheric Subdural Hematoma
}

\author{
Etienne Léveillé, Solon Schur, Ahmed AlAzri, Charles Couturier, Mohamed Maleki, \\ Judith Marcoux
}

\begin{abstract}
Object: Interhemispheric subdural hematomas (IHSDHs) are thought to be rare. Surgical management of these lesions presents a challenge as they are in close proximity to the sagittal sinus and bridging veins. IHSDHs are poorly characterized clinically and their exact incidence is unknown. There are also no clear guidelines for the management of IHSDH. Methods: This is a retrospective review of all admitted patients with a diagnosis of traumatic brain injury over a 4-year period at a Level I trauma centre. Clinical characteristics of all patients with subdural hematoma (SDH) and IHSDH were collected. Results: Of 2165 admissions, 1182 patients had acute traumatic SDHs, 420 patients had IHSDHs (1.9\% of admissions and $35.5 \%$ of SDH), 35 (8.3\% of IHSDH) were $\geq 8$ mm in width. IHSDH was isolated in $16(3.8 \%)$ of the cases. Average age was $61.7 \pm 21.5$ years for all IHSDHs and $77.1 \pm 10.4$ for large IHSDH $(\mathrm{p}<0.001)$. For large IHSDH, a transient loss of consciousness (LOC) occurred in $51.5 \%$ of individuals, post-traumatic amnesia (PTA) in $47.8 \%$ of cases, and motor weakness in $37.9 \%$ of patients. Five of the large IHSDH patients presented with motor deficits directly related to the IHSDH, and weakness resolved in four of these five individuals. None were treated surgically. Progression of IHSDH width occurred in one patient. Conclusion: IHSDHs are often referred to as rare entities. Our results show they are common. Conservative management is appropriate to manage most IHSDHs, as most resolve spontaneously, and their symptoms resolve as well.
\end{abstract}

RÉSUMÉ : Caractérisation clinique d'hématomes sous-duraux interhémisphériques aigus de nature traumatique. Objectif : Les hématomes sous-duraux interhémisphériques (HSDIH) sont considérés comme rares. La prise en charge médico-chirurgicale de ces lésions constitue également un défi dans la mesure où elles sont situées à proximité du sinus sagittal et des veines passerelles (bridging veins). Qui plus est, les HSDIH demeurent mal caractérisés sur le plan clinique tandis que leur impact exact demeure inconnu. Enfin, il n'existe pas de lignes directrices claires quant à leur prise en charge. Méthodes : Il s'agit d'une étude rétrospective portant sur tous les patients admis, au cours d'une période de plus de 4 ans, dans un centre de traumatologie de niveau 1 et chez qui on a posé un diagnostic de traumatisme cranio-cérébral (TCC). À cet égard, nous avons pris soin de collecter les caractéristiques cliniques de tous les patients victimes d'un hématome sous-dural (HSD) ou d'un HSDIH. Résultats : Sur un total de 2165 admissions, 1182 patients avaient été victimes d'un HSD aigu de nature traumatique. Sur ces 1182 patients, mentionnons que 420 d'entre eux souffraient d'HSDIH, ce qui représente $1,9 \%$ de toutes les admissions et 35,5\% des cas de HSD. Chez ces 420 patients, 35 (8,3\%) ont donné à voir des lésions dont la largeur était égale ou supérieure à $8 \mathrm{~mm}$. Les HSDID ont pu être isolés chez seulement 16 cas sur 420, soit 3,8\%. L'âge moyen de tous les patients victimes d'HSDIH était de 61,7 $\pm 21,5$ ans alors qu'il s'est situé à 77,1 $\pm 10,4$ ans pour ceux dont les HSDIH étaient plus larges (p $<0,001)$. Dans le cas justement de ces hématomes plus larges, une perte de conscience transitoire est survenue chez $51,5 \%$ des patients atteints ; dans le cas de ces mêmes patients, 47,8 \% ont souffert d'amnésie post-traumatique alors que 37,9\% ont montré des signes de faiblesse motrice. Finalement, sur tous les patients dont les HSDIH étaient plus larges, 5 d'entre eux ont donné à voir des déficits de la motricité directement liés à leur TCC. Sur ces 5 patients, 4 ont vu leurs signes de fatigue musculaire se résorber. Aucun n'a été pris en charge par la chirurgie et un seul patient a vu la largeur de son HSDIH augmenter. Conclusion : Les HSDIH sont souvent considérés comme des TCC inhabituels. Nos résultats montrent pourtant qu'ils communs. Une prise en charge médicale conservatrice demeure indiquée pour la plupart des HSDIH car la majorité de ces TCC, de même que leurs symptômes, finissent par se résorber spontanément.

Keywords: Subdural hematoma, Interhemispheric hematoma, Head injury, Traumatic brain injury, Intracranial hemorrhage doi:10.1017/cjn.2020.44

Can J Neurol Sci. 2020; 47: 504-510

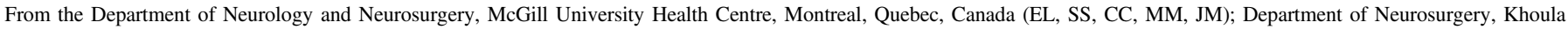
Hospital, Ministry of Health, Muscat, Oman (AA)

Received December 8, 2019. Final Revisions Submitted January 27, 2020. Date of Acceptance February $23,2020$.

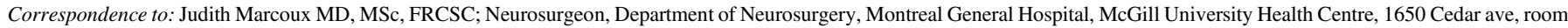
L7-516, Montreal, Quebec, Canada, H3G 1A4. Email: judith.marcoux@mcgill.ca 


\section{INTRODUCTION}

Interhemispheric subdural hematomas (IHSDHs), also known as parafalcine hematoma, are defined as any subdural hematomas (SDHs) present within the interhemispheric space and can be unilateral or bilateral. The classical clinical presentation of an IHSDH is the "falx syndrome" with contralateral hemiparesis predominantly in the lower extremity. Surgical management of these lesions presents a particular challenge: they are in close proximity to the sagittal sinus and numerous bridging veins, and brain retraction is necessary to reach the deeper portion of the hematoma, which can damage eloquent cortex. Fresh hematomas in the interhemispheric space also tend to be more adherent to brain and vascular structures in our experience.

The first reported case of a traumatic IHSDH was published in $1940 .{ }^{1}$ Most of the literature on traumatic IHSDH is made of case reports, with only 13 studies including more than 4 patients. ${ }^{2-14}$ Therefore, the incidence of traumatic IHSDH is thought to be rare. As a consequence, IHSDHs are poorly characterized clinically and their exact incidence is unknown. There are also no clear guidelines for the management of IHSDH. The current Brain Trauma Foundation guidelines for surgical management of traumatic brain injury (TBI) ${ }^{15}$ recommend surgical evacuation of SDH if 1) the SDH is larger than $10 \mathrm{~mm}$ or associated with a midline shift of more than $5 \mathrm{~mm}$ on CT(computed tomography) scan, regardless of the Glasgow Coma Scale (GCS) score $^{16}$ or 2) the SDH is associated with a GCS of less than 9, and also either one of a 2-point decrease in the GCS score, an intracranial pressure higher than $20 \mathrm{mmHg}$, or signs of herniation (pupillary asymmetry). But the current guidelines are based on studies that did not include IHSDH.

Our study aims at clarifying the exact incidence of IHSDH and describing their clinical presentation and evolution, so that a management algorithm could be proposed for this challenging pathology.

\section{MeTHODS}

\section{Patient Population}

The Montreal General Hospital, part of the McGill University Health Centre (MUHC), is one of only three adult tertiary (Level I) trauma centers serving the province of Quebec, Canada, which has a population of almost eight million people. The Montreal General Hospital TBI database and the Trauma Registry Database were used to identify all patients admitted during a 4-year period (December 2009 to December 2013) with a diagnosis of traumatic SDH. We performed a retrospective study of the TBI database, the Trauma Registry Database, and initial CT scans of all patients identified. Furthermore, for all IHSDHs with a width of $8 \mathrm{~mm}$ or more, a detailed chart review was conducted. The MUHC Research Ethics Board (study identifier 14-414GEN) and the Director of Professional Services approved this study and the informed consent requirement was waived.

\section{Patient Management}

All patients with a traumatic SDH were initially evaluated by a dedicated trauma team, and subsequently by the neurosurgery service. Patients requiring immediate surgery, according to the Brain Trauma Foundation guidelines, were directed to the operating room. All the other patients were admitted to the intensive care unit under close observation. All patients with a GCS of 8 or less and an abnormal scan had an intracranial pressure (ICP) monitor placed, according to the Brain Trauma Foundation guidelines. ${ }^{17}$ Appropriate measures to lower the ICP once over $20 \mathrm{mmHg}$ were administered as indicated, including medical interventions and/or decompressive craniectomy. Prophylactic anticoagulation was initiated in nonambulatory patients 48 to 72 hours after trauma, provided there was stability of the intracranial hemorrhagic lesions on two consecutive CT scans. ${ }^{18}$

\section{Data Extraction}

All patients admitted over a period of 4 years (2009-2013) with a diagnosis of traumatic SDH were reviewed. Data such as age, gender, associated intracranial injuries, size of hematoma, GCS score at presentation, Injury Severity Score (ISS) were collected. For patients with large IHSDH $(\geq 8 \mathrm{~mm})$, mechanism of injury, symptoms at presentation (such as alteration of consciousness and lower limb weakness), and coagulation status were also collected. An 8-mm cutoff was taken in order to ensure all potentially symptomatic IHSDHs were reviewed in detail. The management for the IHSDH, whether conservative or surgical, was recorded. The use of antithrombotic medication reversal agents was recorded. The extended Glasgow Outcome Scale (GOSE) score $^{19}$ at discharge from the acute care hospital was also recorded. The GOSE was always assigned according to a consensus within the medical and rehabilitation multidisciplinary team at discharge from the acute care hospital.

\section{Statistical Analysis}

All statistical analyses were performed using SPSS 23.0. Descriptive statistics were reported for all variables as means and standard deviations for numerical variables, and percentages for categorical data. The Pearson $\chi^{2}$ test was used for univariate comparison of binary variables among different subgroups, and the independent samples $t$-test was performed for univariate comparison of continuous variables. Adjustment with necessary covariates was performed using linear regression for continuous variables. Statistical significance was set at $\mathrm{p}<0.05$.

\section{Results}

A total of 2165 patients were admitted during the 4-year period with a diagnosis of TBI, of which $1182(54.5 \%)$ had a diagnosis of acute traumatic SDH. Of these, 420 patients $(35.5 \%$ of all SDHs and $19.4 \%$ of all admitted TBI patients) were found to have an IHSDH, either isolated or concomitant with another traumatic SDH. Of all the IHSDHs, 35 had a width of $8 \mathrm{~mm}$ or more, representing $8.3 \%$ of the IHSDH and $3.0 \%$ of all SDHs (see Figure 1).

\section{IHSDH vs SDH}

Patients' characteristics were similar in IHSDH cases when compared to all patients with SDH (see Table 1). Male patients were younger for both $\mathrm{SDH}(58.1 \pm 21.7$ vs $66.0 \pm 21.0$, $\mathrm{p}<0.001)$ and IHSDH $(58.0 \pm 20.9$ vs $69.4 \pm 20.7, \mathrm{p}<0.001)$. When comparing between patients with an SDH with and without an IHSDH, characteristics were similar, except for the GCS score, where the SDH with IHSDH group had a significantly lower GCS score at presentation (see Table 2). 
Table 1: Patients characteristics for isolated and non-isolated IHDSH

\begin{tabular}{l|c|c|c}
\hline & IHSDH + injury & Isolated IHSDH & p-Value \\
\hline $\mathrm{n}$ & 403 & 17 & $\mathrm{n} / \mathrm{a}$ \\
\hline Age & $61.6 \pm 21.5$ & $62.6 \pm 22.5$ & 0.858 \\
\hline$\%$ Male & 67.7 & 64.7 & 0.793 \\
\hline GCS & $10.8 \pm 4.5$ & $13.8 \pm 3.0$ & $\mathbf{0 . 0 0 1}$ \\
\hline ISS & $28.1 \pm 8.5$ & $24.5 \pm 8.4$ & 0.082 \\
\hline
\end{tabular}

$\%=$ percentage; $\mathrm{GCS}=$ Glasgow Coma Scale score; $\mathrm{IHSDH}=$ interhemispheric subdural hematoma; ISS = Injury Severity Score; $\mathrm{n}=$ number.

Statistically significant differences are highlighted in bold.

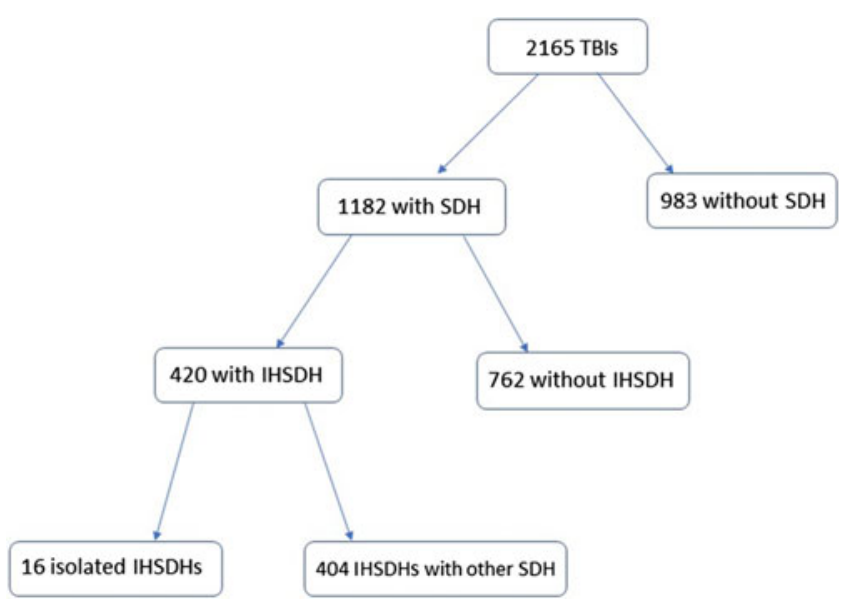

Figure 1: Flowchart showing the incidence of interhemispheric subdural hematomas.TBI = traumatic brain injury (includes all patients admitted with a diagnosis of TBI during the 4-year period; $S D H=$ admitted patients with subdural hematoma; No SDH = admitted patients with a TBI but without a subdural hematoma; IHSDH = admitted patients with an interhemispheric subdural hematoma; Isolated IHSDH=patients with only interhemispheric subdural hematoma as intracranial injury.

\section{Isolated IHSDH vs IHSDH Associated with Other Injuries}

Sixteen patients $(3.8 \%)$ had an isolated IHSDH. IHSDH was associated with another SDH in $90.9 \%$ of the cases. Other injuries found included SAH (68.2\%), intracerebral contusions $(56.8 \%)$, epidural hematoma (1.9\%), and fractures (34.0\%). Patient characteristics were similar between isolated IHSDH and IHSDH associated with other injuries (see Table 3). Patients with an isolated IHSDH had a lower ISS, although the difference was not statistically significant.

\section{Small vs Large IHSDH}

Patients with large IHSDH were significantly older (see Table 4). Males were significantly younger than females for small IHSHD $(58.0 \pm 20.9$ vs $69.4 \pm 20.7 \mathrm{y}, \mathrm{p}<0.001)$, but not for large IHSDH $(77.5 \pm 9.7$ vs $76.5 \pm 12.0 \mathrm{y}, \mathrm{p}=0.790)$. Of the 16 isolated IHSDHs, 13 were small (3.4\% of all small IHSDH) and 3 were large $(8.6 \%$ of all large IHSDH). Large IHSDHs were not significantly more likely to be isolated, compared to small IHSDHs $(p=0.125)$.
Table 2: Patients characteristics for SDH and IHSDH

\begin{tabular}{l|c|c|c}
\hline & SDH & IHSDH & p-Value \\
\hline $\mathrm{n}$ & 736 & 420 & $\mathrm{n} / \mathrm{a}$ \\
\hline Age & $60.5 \pm 21.8$ & $61.7 \pm 21.5$ & 0.387 \\
\hline$\%$ Male & 69.6 & 67.6 & 0.483 \\
\hline GCS & $12.0 \pm 4.0$ & $10.9 \pm 4.5$ & $<\mathbf{0 . 0 0 1}$ \\
\hline ISS & $27.8 \pm 8.8$ & $28.0 \pm 8.5$ & 0.673 \\
\hline
\end{tabular}

$\%=$ percentage; GCS = Glasgow Coma Scale score; IHSDH = interhemispheric subdural hematoma; ISS = Injury Severity Score; $\mathrm{n}=$ number; $\mathrm{SDH}=$ subdural hematoma.

Statistically significant differences are highlighted in bold.

Table 3: Patients characteristics for SDH with and without IHSDH

\begin{tabular}{l|c|c|c}
\hline & SDH w/o IHSDH & SDH + IHSDH & p-Value \\
\hline $\mathrm{n}$ & 737 & 380 & $\mathrm{n} / \mathrm{a}$ \\
\hline Age & $60.5 \pm 21.8$ & $62.2 \pm 21.4$ & 0.231 \\
\hline$\%$ Male & 69.6 & 66.8 & 0.345 \\
\hline GCS & $12.0 \pm 4.0$ & $10.7 \pm 4.6$ & $<\mathbf{0 . 0 0 1}$ \\
\hline ISS & $27.8 \pm 8.8$ & $28.0 \pm 8.2$ & 0.728 \\
\hline
\end{tabular}

$\%=$ percentage; GCS = Glasgow Coma Scale score; $\mathrm{IHSDH}=$ interhemispheric subdural hematoma; ISS = Injury Severity Score; $\mathrm{n}=$ number; $\mathrm{SDH}=$ subdural hematoma; $w / o=$ without.

Statistically significant differences are highlighted in bold.

Table 4: Patients characteristics for small and large IHSDH

\begin{tabular}{l|c|c|c}
\hline & Small IHSDH & Large IHSDH & p-Value \\
\hline $\mathrm{n}$ & 384 & 35 & $\mathrm{n} / \mathrm{a}$ \\
\hline Age & $60.4 \pm 21.6$ & $77.1 \pm 10.4$ & $<\mathbf{0 . 0 0 1}$ \\
\hline$\%$ Male & 68.2 & 62.9 & 0.515 \\
\hline GCS & $10.9 \pm 4.6$ & $11.8 \pm 4.2$ & 0.236 \\
\hline ISS & $28.0 \pm 8.7$ & $27.2 \pm 5.6$ & 0.426 \\
\hline
\end{tabular}

$\%=$ percentage; $\quad$ GCS $=$ Glasgow Coma Scale score; $\mathrm{IHSDH}=$ interhemispheric subdural hematoma; ISS = Injury Severity Score; $\mathrm{n} / \mathrm{a}=$ not applicable; SDH = subdural hematoma.

Statistically significant differences are highlighted in bold.

\section{Clinical Presentation of Large IHSDH and Falx Syndrome}

Fall from own height was by far the most common mechanism of injury in large IHSDH, having occurred in $85.7 \%$ of patients. Antithrombotic agents were used in $69.7 \%$ of cases. A transient loss of consciousness (LOC) was the most common symptom in large IHSDH patients, having occurred in $51.5 \%$ of individuals. Post-traumatic amnesia (PTA) was reported in $47.8 \%$ of cases, while motor weakness was present in $37.9 \%$ of patients. Numbness and anisocoria were rarer, being present in respectively 17.4 and $14.3 \%$ of cases. Average ISS was $27.1 \pm 5.6$ and average 


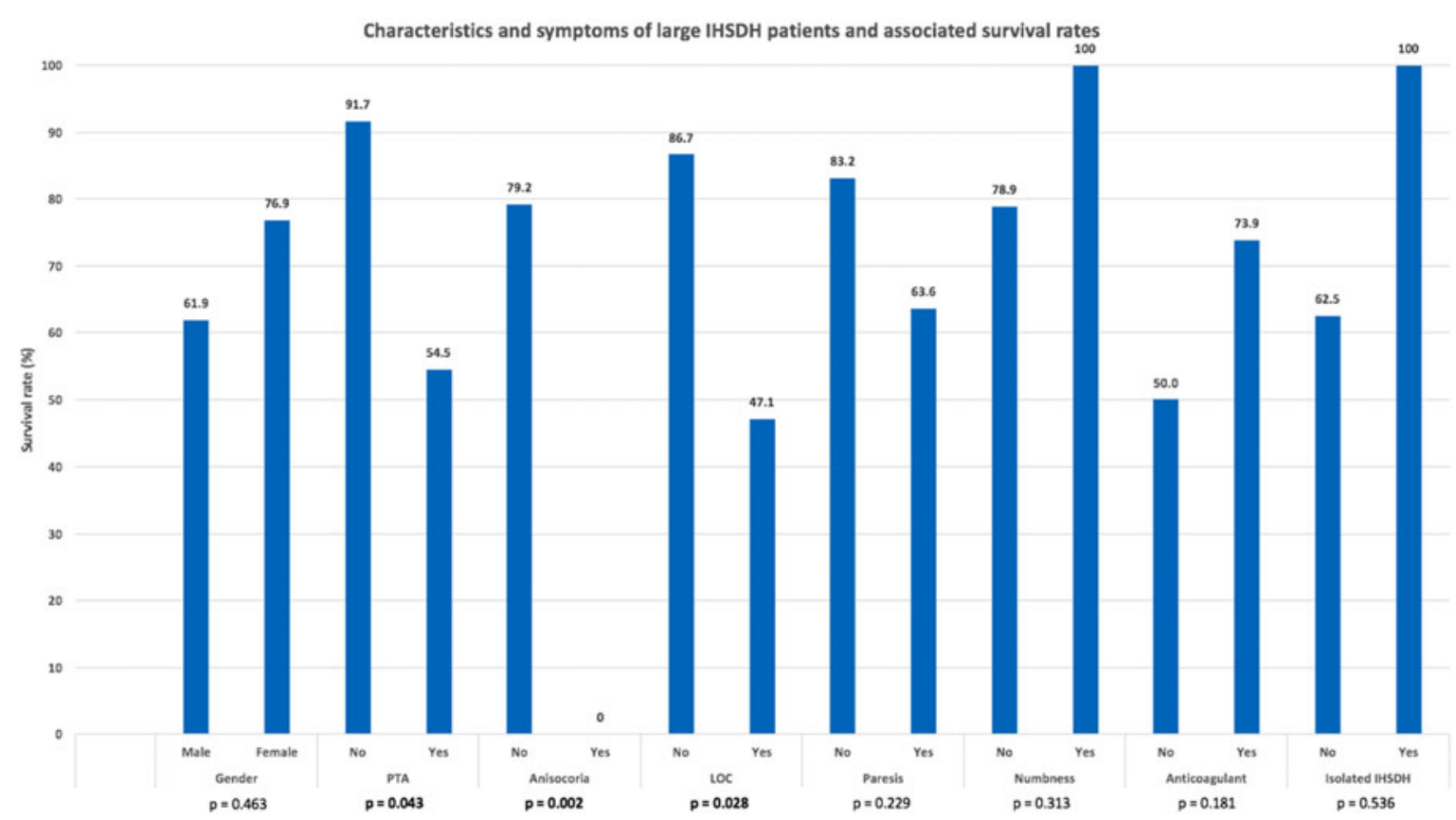

Figure 2: Large interhemispheric subdural hematoma patients' characteristics and clinical presentation. Highlighted $p$ values are statistically significant.GOSE = extended Glasgow Outcome Scale score; IHSDH = interhemispheric subdural hematoma; $L O C=$ loss of consciousness; PTA = post-traumatic amnesia.

GCS score at presentation was $11.8 \pm 4.3$. Sixteen of the 35 patients had a GCS score of 15 at presentation. A decrease in GCS score was identified in $44 \%$ of patients, compared to score at presentation. Two had insertion of external ventricular drain for ICP monitoring as they had GCS below 9 and potentially survivable injuries. They did not develop high ICP.

Five patients presented with motor deficits directly related to the presence of the IHSDH, or falx syndrome (14\% of the large IHSDH). Two patients had 4/5 leg weakness and one had 3/5 leg weakness. One patient had mild leg weakness at presentation but progressed to $0 / 5$ after 9 days. Another patient had hemiplegia and a decreased level of consciousness.

\section{Management}

A total of 115 out of 420 IHSDH patients (27.3\%) underwent surgery, although none were operated for their IHSDH. This includes 8 of the 35 large IHSDH patients (22.9\%), and 107 of the 384 patients with a width under $8 \mathrm{~mm}(27.8 \%)(\mathrm{p}=0.525)$. IHSDHs were conservatively managed, notably by administration of prothrombin complex concentrate and vitamin $\mathrm{K}$ to reverse coagulopathy when required.

\section{Outcome}

Although IHSDH patients presented with a lower GCS score than the total population of $\mathrm{SDH}(12.0 \pm 4.0$ vs $10.9 \pm 4.5$, $\mathrm{p}<0.001)$, GOS score at discharge was similar among the two groups $(4.2 \pm 1.6$ for SDH vs $4.1 \pm 1.8$ for IHSDH, $\mathrm{p}=0.207)$. When comparing between SDH with and without IHSDH, the SDH with IHSDH group had a lower GOS score, although it did not reach statistical significance $(4.0 \pm 1.8$ vs $4.2 \pm 1.6$, $\mathrm{p}=0.073$ ). For patients with IHSDH, the presence of concomitant injuries was associated with a lower GCS score at presentation and a lower GOS score $(4.1 \pm 1.8$ vs $4.8 \pm 1.2$, $\mathrm{p}=0.023)$. The GOS score did not significantly differ between the small and large IHSDH groups $(\mathrm{p}=0.856)$.

\section{Outcomes of Large IHSDH}

The average GOS was $3.23 \pm 1.75$ among all patients, and $4.27 \pm 1.03$ among patients that survived. All three patients with large isolated IHSDH presented with GCS score of 15 and survived. Twelve of the $35(34.3 \%)$ large IHSDH patients did not survive. Six of those presented with very poor neurological status on arrival: one died from a large intraparenchymal hemorrhage, one had diffuse axonal injury caused by a high-speed motor vehicle accident, two were very hemodynamically unstable at presentation, one had a very large convexity SDH with a $2-\mathrm{cm}$ midline shift, one was 92 years old and sustained a major TBI and polytrauma. One of the two patients that was hemodynamically unstable at presentation developed disseminated intravascular coagulation. This patient was also the only one that had an increased IHSDH width at follow-up imaging. However, death was related to the overall burden of injury and not to the IHSDH. Three of the 12 patients that died had a poor baseline level of physically and cognition and only palliative measures were instituted. The last three patients also died of overall burden of injury and not due to the IHSDH. None had surgical intervention for their brain injury. Five factors were associated with a lower Glasgow Outcome Scale (GOS) score in large IHSDH patients: low GCS score at presentation $(\mathrm{p}<0.001)$, LOC, PTA, anisocoria, and presence of another concomitant intracranial hematoma (see Figure 2). GOS score was significantly lower in patients that had lost consciousness $(2.47 \pm 1.74$ vs $4.27 \pm 1.28$, $\mathrm{p}=0.002)$ and suffered from PTA $(2.90 \pm 1.92$ vs $4.42 \pm 0.90$, $\mathrm{p}=0.033$ ), and markedly lower in patients presenting with 


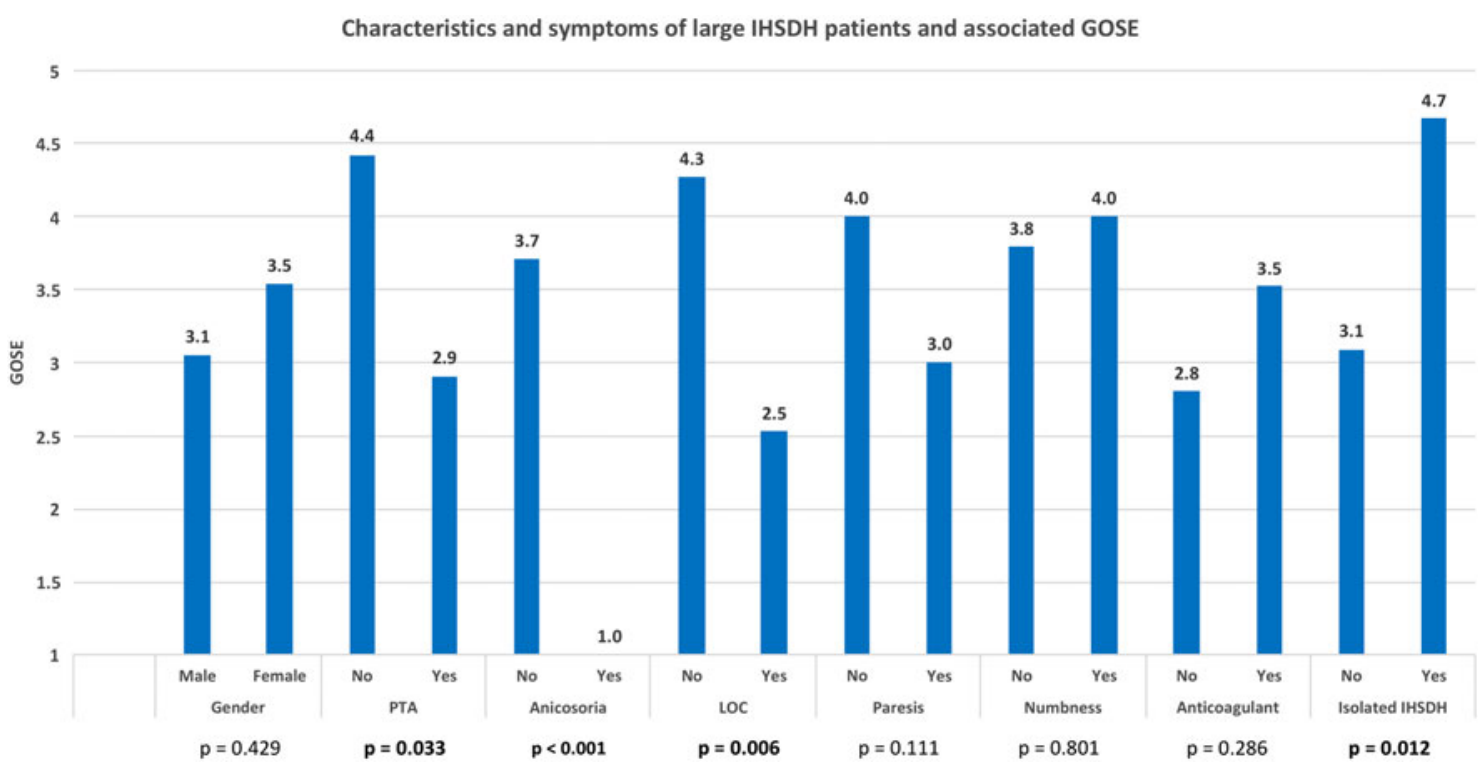

Figure 3: Survival rate of large interhemispheric subdural hematoma according to patients' characteristics and clinical presentation. Highlighted $p$ values are statistically significant.GOSE = extended Glasgow Outcome Scale score; IHSDH $=$ interhemispheric subdural hematoma; LOC = loss of consciousness; PTA = post-traumatic amnesia.

anisocoria $(1.00 \pm 0.00$ vs $3.71 \pm 1.55, \mathrm{p}<0.001)$. Patients with large isolated IHSDH had a better outcome than patients with other concomitant intracranial hemorrhage (GOS score: $4.67 \pm 0.58$ vs $3.09 \pm 1.77, \mathrm{p}=0.012$ ). Age, gender, ISS, IHSDH width, paresis, sensory impairment, and anticoagulant usage did not significantly influence the GOS score of large IHSDH patients.

Four of the five factors associated with lower GOS score in large IHSDH patients were also associated with an increased mortality: low GCS score at presentation, LOC, PTA, and anisocoria (see Figure 3). GCS score at presentation was $13.4 \pm 2.8$ for patients who survived and was significantly lower for patients who did not $(8.9 \pm 5.1, \mathrm{p}=0.014)$. Survival rate was lower for patients that had lost consciousness $(47.1 \%$ vs $86.7 \%$, $\mathrm{p}=0.028)$ or suffered from PTA $(54.5 \%$ vs $79.2 \%)$. Anisocoria was a strong predictor of mortality, as none of the four patients presenting with this symptom survived $(0.0 \%$ vs $79.2 \%$, $\mathrm{p}=0.002$ ). Sex, age, anticoagulation status, IHSDH width, ISS, paresis, and numbness were not significantly correlated with survival. All three patients with isolated large IHSDH presented with GCS scores of 15 and survived, although survival rate was not significantly higher $(\mathrm{p}=0.536)$ than individuals with large IHSDH associated with other injuries.

\section{IHSDH Width at Follow-Up}

CT scan data at follow-up was available for 277 IHSDH patients. Hematoma width had decreased by an average $93.5 \%$ at follow-up. The average timing for follow-up was 7.0 weeks after the initial traumatic event. The hematoma had completely resorbed in 240 patients (86.6\%) at an average of 7.5 weeks of follow-up. Progression of IHSDH size only occurred in one patient, in whom the follow-up CT scan was performed after 2 weeks, and the hematoma had progressed from 4 to $5 \mathrm{~mm}$ in thickness. IHSDH resorption occurred at a significantly slower

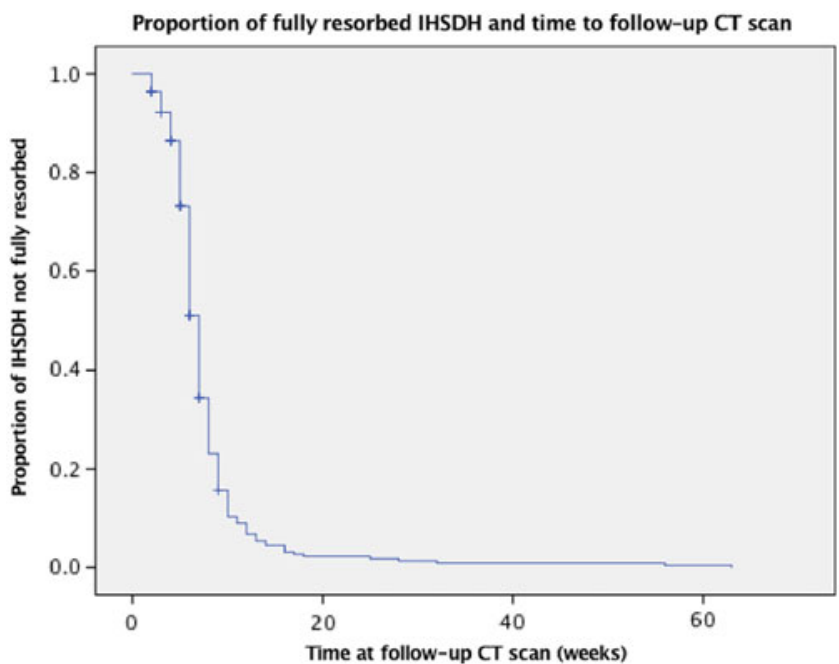

Figure 4: Kaplan-Meier curve of number of residual hematoma at follow-up. $C T=$ computed tomography; IHSDH = interhemispheric subdural hematoma.

rate in male patients, after adjustment for time to follow-up CT scan $(p=0.020)$. Age $(p=0.242)$, ISS $(p=0.834)$, GCS score at presentation $(p=0.953)$, initial IHSDH width $(p=0.078)$, and the presence of associated injuries $(p=0.719)$ did not influence the resorption of IHSDH. The proportion of IHSDH size decrease at follow-up did not significantly influence the GOS score of patients $(\mathrm{p}=0.162)$.

When conducting Kaplan-Meier analysis (see Figure 4), $13.4 \%$ did not fully resorb at $\mathrm{f} / \mathrm{u}$. The proportion of large IHSDH that did not fully resorb was $31.8 \%$, compared to $11.8 \%$ for the small SDH $(\mathrm{p}=0.029)$. SDHs resorb less in male patients (16.6\% not fully resorbed) than in female patients 
(6.7\%), but this difference was not significant $(\mathrm{p}=0.596)$. SDH associated with other injuries did not resorb less than isolated SDH. $(p=0.607)$

\section{IHSDH-Related Symptoms at Follow-Up}

The two patients who had a 4/5 leg weakness and the one who had a 3/5 leg weakness recovered fully within 1 month. The one patient who initially had mild leg weakness but progressed to $0 / 5$ after 9 days recovered strength at $4 / 5$ by 2 months and made a full recovery at the 3-month follow-up. The patient who presented with hemiplegia and a decreased level of consciousness recovered some strength and was at $3 / 5$ after 2 months. Of note, this patient's general health and functional status were poor before the injury.

\section{Discussion}

To our knowledge, this is the first study to report and clinically characterize such a large number of patients with IHSDH. Our analysis reveals that, despite what has previously been reported in the literature, acute IHSDH is a common entity, being present in more than $35 \%$ of acute $\mathrm{SDH}$ requiring admission and in $19.4 \%$ of all admitted TBI patients. In contrast, out of 4312 hospitalizations for head trauma, Takeuchi et al. reported only 35 cases of traumatic IHSDH out of 4315 hospitalized patients over 14 years, representing $0.8 \%$ of TBIs. ${ }^{4}$ Takeda et al. reported 48 cases of acute SDH, including 3 IHSDHs (6\%). ${ }^{20}$ This is likely due to the fact that only IHSDHs as a main diagnosis were counted, whereas in our study, all images were reviewed to detect the presence of an IHSDH. In our study, large IHSDHs ( $>8 \mathrm{~mm}$ ) were less common but still not rare, being present in $3.5 \%$ of all acute SDHs. IHSDHs most commonly occur concurrently with other types of intracranial hematoma and isolated IHSDHs remain rare, representing $0.88 \%$ of all TBIs in the present study and $0.90 \%$ of all TBIs reported by Howard et al. ${ }^{3}$

As it is the case for convexity SDH, IHSDH occurred predominantly in males and showed a bimodal incidence pattern with peaks in the third decade of life and the elderly. Compared to SDHs in general, IHSDHs were associated with a lower GCS score. Large IHSDH did not show a bimodal incidence pattern and mostly occurred in older individuals using anticoagulants. A lower GCS in IHSDH might be explained by the fact that IHSDHs tend to occur in a more vulnerable population (older individuals, sicker at baseline). It is possible also that a more forceful mechanism is otherwise necessary to produce an IHSDH in a younger population. IHSDHs are often associated with other injuries and patients and therefore may present with a lower GCS score, compared to convexity SDH.

Clinical presentation with a falx syndrome was uncommon in our series, being present in only $14 \%$ of the large IHSDH. In the study from Takeushi et al., ${ }^{4} 6 \%$ presented with falx syndrome. However, the sizes of IHSDH were not reported. Anh et $\mathrm{al}^{2}$ report a series of 105 IHSDHs, with 42 patients having IHSDH thickness of $3 \mathrm{~mm}$ or more. Eight of these 42 were nontraumatic in origin. Only two patients presented with the so-called falx syndrome and most presented with a GCS of 13 or above.
Most IHSDHs, especially when they are isolated, seem to follow a benign course. IHSDH width progression is rare, having occurred in only one patient in the present study, and in none of the patients reported by Bajsarowicz et al. ${ }^{14}$ and Inamasu et al. ${ }^{9}$ Another recent publication looked at IHSDH presenting in a Level I trauma centre and the need for intensive monitoring. The authors report a series of 28 isolated traumatic IHSDHs with an average thickness of $4.4 \mathrm{~mm}$, and only 2 cases of thickness above $1 \mathrm{~cm}$. Clinical and radiological follow-up showed that none of the IHSDHs progressed. ${ }^{3}$

Conservative management was preferred for all IHSDHs due to the close proximity of the hematomas to crucial structures such as the sagittal sinus, because of their catastrophic presentation or poor status at baseline. All patients who presented with focal deficit (lower extremity weakness) related to the IHSDH made significant improvements. In their series, Takeushi et al. ${ }^{4}$ reported that all their IHSDHs were treated with conservative management, and $57 \%$ had a favorable outcome with a GOS of 4 or 5 . On the contrary, Wang et al. ${ }^{5}$ published a series of 21 cases that were all treated surgically, out of 6840 cases over 10 years. The mean hemorrhage thickness was $13 \mathrm{~mm}$, and a favorable outcome was reached in $86 \%$ of the cases. However, the exact criteria for the decision to operate were not given, and the authors did not account for the natural history of the disease. In the series of 105 IHSDHs by Anh et al., 22 patients required surgical intervention for concurrent lesions (usually convexity SDH) but none of the IHSDHs were surgically evacuated. The management with or without surgical evacuation of these lesions remains therefore controversial. While a majority of IHSDHs do not require intervention, even when symptomatic, some IHSDHs causing significant local and global mass effect may benefit from surgical evacuation.

Five clinical characteristics were predictors of poor outcome for large IHSDH in the current study: transient LOC, PTA, low GCS score, anisocoria, and concomitant intracranial hematoma. The prognostic value of GCS score at presentation in IHSDH has already been reported. ${ }^{2,4,5}$ In addition to the GCS score, Takeuchi and al. identified hypovolemic shock, skull fracture, convexity or posterior fossa $\mathrm{SDH}$, and the presence of concomitant $\mathrm{SAH}$ as poor outcome predictors for IHSDH of any size, and Wang et al. reported an association between IHSDH width and outcome for surgically managed cases. Coagulopathy was associated with poor outcome in a study of $14 \mathrm{IHSDH}$ cases by Novak et al. ${ }^{7}$ IHSDH width and the presence of coagulopathy were not significant prognostic factors in large IHSDH cases reported in the present study.

\section{Conclusion}

The great majority of IHSDHs were small and caused no symptoms or mild symptoms and should be managed without surgery. Even larger IHSDH caused minimal to no symptoms in most patients and only a minority presented with a typical falx syndrome (1.2\% of all IHSDHs and $14.3 \%$ of the large IHSDH). Of those, only one did not recover fully from the weakness, and that patient also had decreased level of consciousness. Surgical evacuation of the IHSDH could be considered in patients with decreased level of consciousness related to IHSDH mass effect. 
IHSDH progression is very rare and was observed in only one one patient.

\section{Disclosure}

None of the authors has any competing financial interests.

\section{REFERENCES}

1. Aring CD, Evans JP. Aberrant location of subdural hematoma. Arch NeurPsych. 1940;44:1296-306.

2. Ahn JM, Lee KS, Shim JH, Oh JS, Shim JJ, Yoon SM. Clinical features of interhemispheric subdural hematomas. Korean J Neurotrauma. 2017;13:103-7.

3. Howard BM, Rindler RS, Holland CM, Pradilla G, Ahmad FU. Management and outcomes of isolated tentorial and parafalcine "Smear" subdural hematomas at a Level-1 trauma center: necessity of high acuity care. J Neurotrauma. 2017;34:128-36.

4. Takeuchi S, Takasato Y, Masaoka H, Hayakawa T, Yatsushige H, Sugawara T. Traumatic interhemispheric subdural haematoma: study of 35 cases. J Clin Neurosci : Official J Neurosurg Soc Australas. 2010;17:1527-9.

5. Wang Y, Wang C, Cai S, et al. Surgical management of traumatic interhemispheric subdural hematoma. Turkish Neurosurg. 2014;24:228-33.

6. Numerow LM, Fong TC, Wallace CJ. Pseudodelta sign on computed tomography: an indication of bilateral interhemispheric hemorrhage. Can Assoc Radiol J = Journal l'Association canadienne des radiologistes 1994;45:23-7.

7. Novak Z, Chrastina J, Kriva T, Shaqbua M. [Interhemispheric subdural haematoma]. Rozhledy v chirurgii : mesicnik Ceskoslovenske chirurgicke spolecnosti 2007;86:63-7.

8. Senel A, Cokluk C, Onder A, Iyigun O, Incesu L. Acute interhemispheric subdural hematomas. Report of nine cases. J Neurosurg Sci. 2001;45:97-102.

9. Inamasu J, Nakaya M, Kujirai D, Mayanagi K, Nakatsukasa M. Frequency and characteristics of traumatic brain injury in restrained drivers involved in road traffic accidents. Acta Neurochir. 2018;160:1921-9.

10. Iplikcioglu AC, Bayar MA, Kokes F, Doganay S, Gokcek C. Interhemispheric subdural haematomas. British $\mathrm{J}$ Neurosurg. 1994;8:627-31.

11. Houtteville JP, Toumi K, Theron J, Derlon JM, Benazza A, Hubert P. Interhemispheric subdural haematomas: seven cases and review of the literature. British J Neurosurg. 1988;2:357-67.

12. Vaz R, Duarte F, Oliveira J, Cerejo A, Cruz C. Traumatic interhemispheric subdural haematomas. Acta Neurochir. 1991;111: $128-31$.

13. Borzone M, Altomonte M, Baldini M, Rivano C. Typical interhemispheric subdural haematomas and falx syndrome: four cases and a review of the literature. Zentralblatt fur Neurochir. 1995;56:51-60.

14. Bajsarowicz P, Prakash I, Lamoureux J, et al. Nonsurgical acute traumatic subdural hematoma: what is the risk? J Neurosurg. 2015;123:1176-83.

15. Bullock MR, Chesnut R, Ghajar J, et al. Surgical management of acute subdural hematomas. Neurosurgery. 2006;58:S16-24; discussion $\mathrm{Si}$-iv.

16. Teasdale G, Jennett B. Assessment of coma and impaired consciousness. A practical scale. Lancet. 1974;2:81-4.

17. Brain Trauma F, American Association of Neurological S, Congress of Neurological S, et al. Guidelines for the management of severe traumatic brain injury. VII. Intracranial pressure monitoring technology. J Neurotrauma. 2007;24(Suppl 1):S45-54.

18. Dudley RR, Aziz I, Bonnici A, et al. Early venous thromboembolic event prophylaxis in traumatic brain injury with low-molecularweight heparin: risks and benefits. J Neurotrauma. 2010;27: 2165-72.

19. Wilson JT, Pettigrew LE, Teasdale GM. Structured interviews for the Glasgow Outcome Scale and the extended Glasgow Outcome Scale: guidelines for their use. J Neurotrauma. 1998;15:573-85.

20. Takeda N, Kurihara E, Matsuoka H, Kose S, Tamaki N, Matsumoto S. [Three cases of acute interhemispheric subdural hematoma]. No Shinkei Geka 1988;16:87-92. 